\title{
MiR-495 is a Predictive Biomarker that Downregulates GFI1 Expression in Medulloblastoma
}

\author{
Ce Wang $^{\mathrm{a}}$ Zhiyuan Yun ${ }^{\mathrm{b}}$ Tianshu Zhao ${ }^{\mathrm{a}}$ Xian Liua Xueling Ma \\ aDepartment of Neurosurgery, The Fourth Affiliated Hospital of Harbin Medical University, Harbin, \\ ${ }^{b}$ Department of General Medicine, Harbin Medical University Cancer Hospital, Harbin, 'Department of \\ Neurology, The Fourth Affiliated Hospital of Harbin Medical University, Harbin, China
}

\section{Key Words}

Medulloblastoma $\cdot$ miR-495 Predictive biomarker $•$ Prognosis

\begin{abstract}
Background: Alterations in the expression level of miR-495 were recently observed in various tumours. Medulloblastoma is the most common malignant brain tumour in children. However, the clinical significance of miR-495 in medulloblastomas remains unclear. Methods: The expression levels of miR-495 was examined in 62 archival formalin-fixed paraffin-embedded (FFPE) medulloblastoma specimens using TaqMan Real-time Quantitative PCR arrays. Immunohistochemistry was used to determine the expression of Gfi1 in medulloblastoma tissues, and a luciferase reporter assay was carried out to confirm whether Gfil is a direct target of miR-495. Results: MiR-495 expression is repressed in medulloblastoma samples compared with normal cerebellum tissues. Furthermore, patients with a low level of miR495 showed significantly poorer survival, as determined by the log-rank test $(P=0.033)$. The multivariate analysis results showed that the miR-495 expression levels were an independent predictor of overall survival in medulloblastoma patients $(P=0.027$; hazard ratio $=0.267$ ). Our study provides the first demonstration that miR-495 directly interacts with the Gfi1 3'UTR to regulate Gfil at a post-transcriptional level and that the expression level of miR-495 is inversely correlated with the Gfi1 protein level in medulloblastoma specimens. Conclusion: Our results suggest that miR-495 may be a prognostic predictor in medulloblastoma and that Gfi1 is a potential functional target of miR-495.

Copyright $@ 2015$ S. Karger AG, Basel
\end{abstract}

\section{Introduction}

Medulloblastomas constitute the most common malignant embryonal brain tumour in children $[1,2]$. This tumour is a highly invasive primitive neuroectodermal tumour arising

C. Wang and Z. Yun contributed equally to this work.

Xueling Ma

KARGER 125
Department of Neurology, The Fourth Affiliated Hospital of Harbin Medical University, Nangang District, Harbin, Heilongjiang Province, 150001 (China)

Tel. +86-451-85939452, Fax +86-451-85939452, E-Mail marlenexl@163.com 
in the cerebellum. Current treatment protocols include surgical resection, radiotherapy and chemotherapy. Although the cure rates have improved in recent years, survival of therapyresistant disease remains poor, and survivors suffer from serious long-term side effects of the therapy. The molecular mechanisms that confer tumours either sensitivity or resistance to these treatments remain unclear [3-5]. Thus, a major challenge in neuro-oncology involves the identification of biomarkers that will facilitate this prediction.

MicroRNAs (miRNAs) are endogenous noncoding RNAs that have emerged as key regulators during the development of both normal tissues and tumours [6-9]. They bind to partially complementary sequences within the 3'-untranslated regions (UTR) of target mRNAs to induce transcript degradation or translational repression. Moreover, previous studies have shown that miRNAs can be reliably stable in formalin-fixed paraffin embedded (FFPE) tissues and present an excellent correlation between miRNA expression in fresh frozen and FFPE tissues [10-12]. The specific miRNA expression signatures in brain tumours have received great attention in the last few years and can facilitate the diagnosis and prediction of the therapy response and prognosis [10]. It has been reported that the expression of some miRNAs is associated with survival in medulloblastoma patients $[11,13,14]$.

A low expression of miR-495 has been observed in glioblastoma, non-small cell lung cancer (NSCLC), acute myeloid leukaemia (AML), gastric cancer and prostate cancer [1519]. Additionally, miR-495 has been shown to enhance sensitivity to chemotherapeutic agents in NSCLC [20]. Although many studies indicate a tumour-suppressor activity for miR-495 in tumours, conflicting data exist, and the role of miR-495 function appears to be tumour-specific. miR-495 was also found to be upregulated in hepatocellular carcinoma [21]. However, the expression of miR-495 and its functional targets and its correlation with overall survival in medulloblastoma remains unclear. This study demonstrates that miR-495 can act as an independent prognostic biomarker for medulloblastomas from archived FFPE tissues.

\section{Materials and Methods}

\section{Patients and samples}

This study was approved by the Institutional Review Board of Harbin Medical University, and the subjects provided informed consent. All of the patients underwent surgical resection and the diagnosis of medulloblastoma and histologic subtypes were determined in accordance with the $2007 \mathrm{WHO}$ classification of tumors of the central nervous system. The characteristics of the patients are listed in Table 1. Of importance, all of the patients underwent radiation therapy. Tumour tissues were obtained by surgical resection. Seven control cerebellum tissue samples from areas surrounding the cerebellar contusion or haemorrhage were collected from Harbin Medical University. The prognosis was evaluated in all medulloblastoma patients with formalin-fixed paraffin-embedded (FFPE) samples in June 2014, and follow-up data were available for 62 cases. The extent of resection was graded as gross total resection (GTR) or non-GTR using MRIs obtained within $72 \mathrm{~h}$ of surgical resection by two independent radiologists.

\section{Cell culture and transfection}

DAOY and D283 cells (ATCC, USA) were grown in DMEM and RPMI-1640, respectively, supplemented with 10\% FBS and 1\% Pen-Strep (Invitrogen, USA) in a 5\% $\mathrm{CO}_{2}$ incubator. The cells were transfected with either miR-495 mimics or negative control miRNA (miR-NC, GenePharma, China) using the Lipofectamine 2000 reagent (Invitrogen, USA) following the manufacturer's instructions.

RNA extraction and quantitative real-time PCR ( $q R T-P C R$ )

The total RNA from FFPE tissues was extracted using the mirVana miRNA Isolation Kit (Ambion, USA) according to the manufacturer's protocol. The RNA concentration and quality were determined using a NanoDrop ND-1000 spectrophotometer (NanoDrop Technologies, USA). The miR-495 expression level was determined by TaqMan-based qRT-PCR. The primers and probes for has-miR-495 and U6 rRNA endogenous controls in the TaqMan miRNA assays were purchased from Applied Biosystems, and qRT-PCR 


\section{Cellular Physiology Cell Physiol Biochem 2015;36:1430-1439 \begin{tabular}{l|l} 
and Biochemistry Publisned onIIne: July U6, 2015, 2015 & $\begin{array}{l}\text { C 2015 S. Karger AG, Basel } \\
\text { www.karger.com/cpb }\end{array}$ \\
\hline
\end{tabular} \\ Wang et al: MIR-495 IS A Predictive Biomarker of Medulloblastoma}

was performed in the ABI 7500HT fast real-time PCR System (Applied Biosystems, USA) according to the manufacturer's instructions. The relative level of miR-495 was calculated using the $2^{-\Delta \Delta \mathrm{Ct}}$ method.

\section{Western blotting assay}

The proteins from human medulloblastoma tissues or cells were extracted and characterized through western blot analysis. The lysate was separated by $10 \%$ sodium dodecyl sulphate polyacrylamide gel electrophoresis, and the gel was blotted onto a polyvinylidene difluoride membrane (Millipore, USA). The membrane was incubated with rabbit-anti Growth Factor Independence 1 (Gfi1, Abcam, USA), and glyceraldehyde-3-phosphate dehydrogenase (GAPDH, Abcam, USA) was used as a control. The secondary antibody conjugated with horseradish peroxidase (1:10,000; Santa Cruz Biotechnology, USA) was applied for $1 \mathrm{~h}$ at room temperature. The blots were developed using ECL (PE Life Science, USA). The final results are expressed as fold changes normalized to the control values.

Plasmid constructs and luciferase reporter assay

The 3'-untranslated region (3'-UTR) of Gfi1 and a mutation sequence were synthesized by Sangon (Shanghai, China). The sequence was inserted into the psi-CHECK-2 vector (Promega, USA) at two restriction sites for Xho1 and Not1. The wild-type plasmid containing the 3'-UTR of Gfi1 with the complementary sequence of miR-495 (psi-Gfi1 3'-UTR wild) was created, and a mutant plasmid containing the mutation sequence without a complementary sequence of miR-495 (psi-Gfi1 3'-UTR mut) was generated.

For the luciferase reporter assays, DAOY cells were co-transfected in 24-well plates using the Lipofectamine 2000 reagent (Invitrogen, USA) with $0.5 \mu \mathrm{g}$ of the reporter plasmid and miR-495 mimics or miR-NC at a final concentration of $50 \mathrm{nM}$. Forty-eight hours after transfection, the cells were lysed, and the relative luciferase activity was assessed using the Dual-Luciferase Assay Reporter System (Promega, China). The experiments were performed independently in triplicate.

\section{Immunohistochemistry}

FFPE medulloblastoma tissues were immunostained using the streptavidin-biotin immunoperoxidase assay to detect Gfi1 expression. Anti-Gfi1 (Abcam, USA) antibodies were used for immunohistochemistry. The slides were individually reviewed and scored by two independent observers. The staining intensity in tumour cells was graded as 0 (no staining), 1 (weak, light yellow), 2 (moderate, yellowish brown), or 3 (strong, brown). The proportion of positively stained tumour cells was scored as 0 (no positive tumour cells), 1 ( $<10 \%$ positive tumour cells), 2 ( $10-30 \%$ positive tumour cells), or 3 ( $>30 \%$ positive tumour cells). The staining score was determined by multiplying the staining intensity by the proportion of positively stained tumour cells. High Gfi1 expression was defined as a staining score greater than 4, whereas low expression was defined as a staining score of at most 4 . The final immunostaining score was the average of that obtained by each of the two observers.

\section{Statistical analysis}

All of the statistical analyses were performed using IBM SPSS 19.0 or GraphPad Prism. Associations between miR-495 expression and clinicopathological characteristics were analysed by Fisher's exact test and Wilcoxon rank sum test. The correlation between miR-495 and Gfi1 expression was evaluated using Kendall's correlation coefficient. Survival curves were estimated using the Kaplan-Meier method, and the differences between survival curves were tested using the log-rank test. Prognostic impact of variables on overall survival was evaluated on the basis of hazard ratios and 95\% CIs from unadjusted Cox's proportional hazards regression model. Variables that reached statistical significance in the univariate analysis, as well as clinically important variables, were included into the adjusted multivariate Cox's proportional hazards regression models. Statistical significance was set to $\mathrm{P}<0.05$.

\section{Results}

Clinical Features of Patients

Patient characteristics of the sixty-two study patients are summarised in Table 1. Their ages in years at diagnosis ranged from 5 months to 57 years, with a mean age of 9.5 years 
Table 1. The characteristics of the patients. Abbreviations: GTR, gross total resection; STR, subtotal resection

\begin{tabular}{lccc}
\hline \multicolumn{2}{c}{ Variable } & n & $\%$ \\
\hline Total no. of cases & & 62 & $100 \%$ \\
Gender & Male & 38 & $61.29 \%$ \\
& Female & 24 & $38.71 \%$ \\
Age in years at diagnosis & Infants<3.0 & 4 & $6.45 \%$ \\
& Children 3.0 to 16.0 & 52 & $83.87 \%$ \\
Histology & Adults>16 & 6 & $9.68 \%$ \\
& Classic & 45 & $72.58 \%$ \\
Metastatic stage & Large cell/anaplastic & 8 & $12.9 \%$ \\
Resection & Nodular/desmoplastic & 9 & $14.52 \%$ \\
& M0 & 51 & $82.26 \%$ \\
miR-495 & M+ & 11 & $17.74 \%$ \\
& GTR & 54 & $87.1 \%$ \\
& STR & 8 & $12.9 \%$ \\
& Low & 26 & $41.94 \%$ \\
& High & 36 & $58.06 \%$ \\
\hline
\end{tabular}

(median 8 years). Of the patients, fifty-six (90.32\%) were in the paediatric age group (less than 16 years), including four less than three years, and 6 (9.68\%) were adults. Thirty-eight $(61.29 \%)$ were men and twenty-four $(38.71 \%)$ women. Forty-five tumors $(72.58 \%)$ were classified as classic medulloblastoma, $8(12.9 \%)$ had the large-cell/anaplastic variant, and 9 $(14.52 \%)$ had the desmoplastic variant. The follow-up period ranged from 2 to 239 months (median 52 months). Twenty-three (37.1\%) patients died due to tumor progression and the disease at the last follow-up evaluation. The 5-year overall survival rate of all patients was $66.7 \pm 6.1 \%$.

Expression of miR-495 is decreased in medulloblastoma tissues and cell lines

The expression of miR-495 in 62 medulloblastoma tissue samples was determined by qRT-PCR. The results showed that the relative expression of miR-495 in medulloblastoma was significantly lower compared with that observed in normal cerebellum tissues $(\mathrm{P}<$ 0.001 , Fig. 1A). DAOY and D283 medulloblastoma cell lines also demonstrated significantly lower levels of miR-495 expression compared with normal cerebellum tissues $(\mathrm{P}<0.05$, Fig. 1B).

Low-expression of miR-495 confers poor prognosis

To analyse the association between miR-495 expression and clinicopathological parameters in medulloblastomas, we classified the medulloblastoma specimens with miR-495 levels lower than the median expression level as belonging to the low-miR-495expression group, whereas the specimens with miR-495 levels equal to at least the mean level were classified as belonging to the high-miR-495-expression group. Furthermore, the relationship between miR-495 expression and overall survival in 62 medulloblastoma patients was determined through a Kaplan-Meier survival curve analysis with a logrank test. The 5-year overall survival rate of patients with high miR-495 expression was $84.4 \pm 8.3 \%$, compared with only $58.5 \pm 7.8 \%$ for patients with low miR-495 expression. The low-miR-495-expression group exhibited poorer survival compared with the high-miR-495expression group, which presented longer survival times (Fig. 2). 
Fig. 1. The expression of miR-495 in 62 human medulloblastoma specimens (A) and cell lines (B) relative to that found in normal cerebellum tissues (NCTs) was determined by qRT-PCR. ${ }^{*} \mathrm{P}<0.05$; $* * \mathrm{P}<0.001$.

Fig. 2. Kaplan-Meier survival curves for 62 medulloblastoma patients stratified by the miR-495 expression levels. The log-rank test was used to determine the statistical significance.


Table 2. Survival analysis of miR-495 and clinicopathologic parameters in medulloblastomas. Abbreviations: GTR, gross total resection; LC/A, large-cell/anaplastic; STR, subtotal resection

\begin{tabular}{lcccccc}
\hline \multicolumn{1}{c}{ Variable } & \multicolumn{3}{c}{ Univariate } & & \multicolumn{2}{c}{ Multivariate } \\
& HR & $95 \%$ PI & $p$ Value & HR & $95 \%$ PI & $p$ Value \\
\hline Gender (male v female) & 1.288 & $0.553-2.997$ & 0.558 & 1.278 & $0.512-3.188$ & 0.599 \\
Age (infants v children/ adults) & 0.383 & $0.112-1.315$ & 0.127 & 0.272 & $0.073-1.015$ & 0.053 \\
Histologic subtypes (Desmoplastic v classic + LC/A) & 0.815 & $0.242-2.746$ & 0.741 & 0.474 & $0.122-1.841$ & 0.281 \\
Resection (GTR v STR) & 0.900 & $0.267-3.035$ & 0.866 & 0.878 & $0.228-3.388$ & 0.850 \\
M stage (M+ v M0) & 3.910 & $1.616-9.465$ & 0.002 & 4.459 & $1.746-11.385$ & 0.002 \\
miR-495 (high v low) & 0.326 & $0.110-0.964$ & 0.043 & 0.267 & $0.083-0.859$ & 0.027 \\
\hline
\end{tabular}

MiR-495 is an independent prognostic biomarker for medulloblastoma

To determine the prognostic value of the miR-495 expression level in medulloblastoma, univariate and multivariate analyses were performed. The univariate analysis demonstrated that high levels of miR-495 expression can be considered a "protective" factor in medulloblastoma ( $\mathrm{p}=0.043, \mathrm{HR}=0.326,95 \% \mathrm{CI}=0.110-0.964$, Table 2$)$. The subsequent multivariate Cox proportional hazards analysis further confirmed the findings from the univariate analysis, indicating that the miR-495 expression level is an independent and 


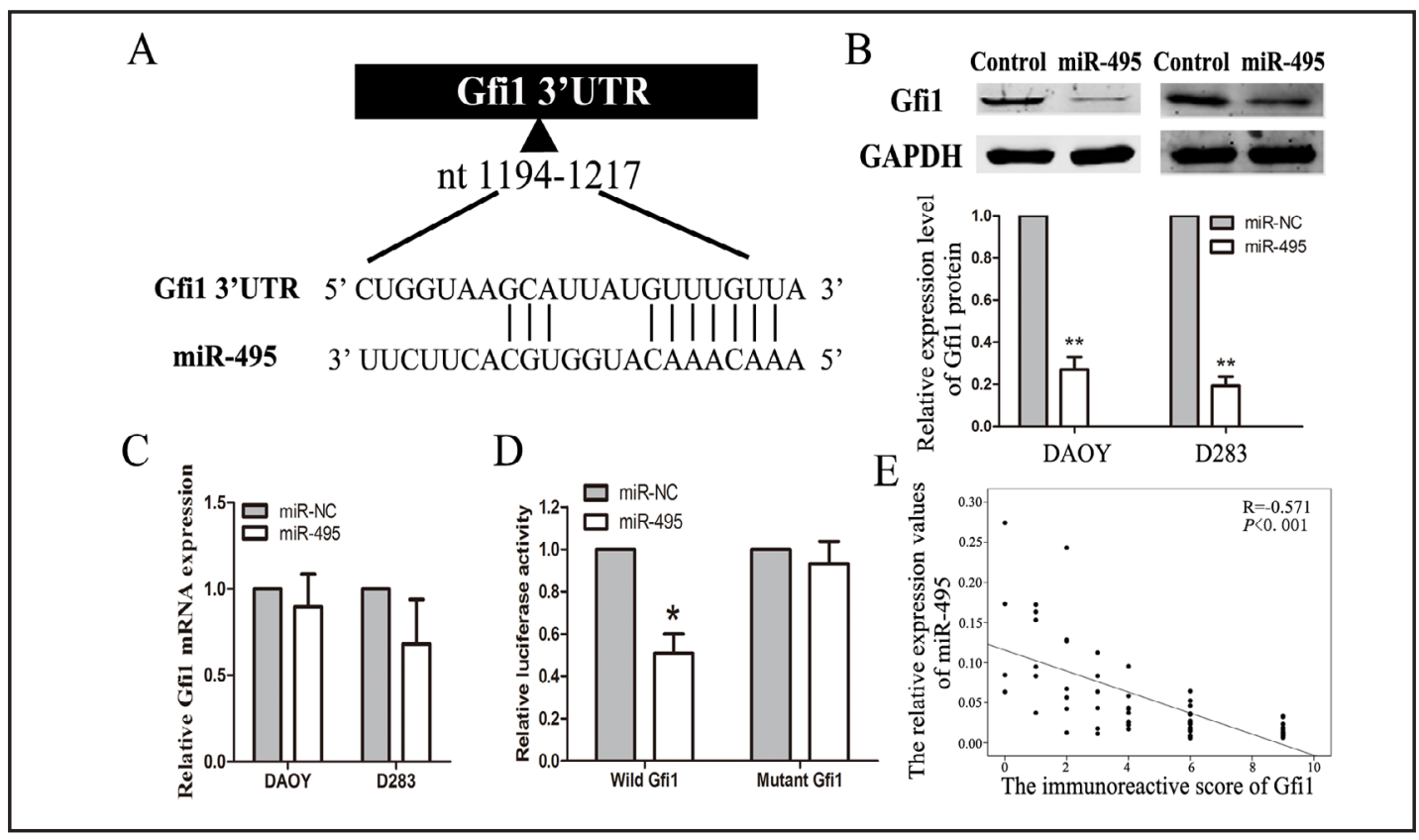

Fig. 3. Gfi1 is a direct target of miR-495 in medulloblastoma. (A) Potential interaction between miR-495 and putative binding sites in the Gfi1 3'UTR. (B) The Gfi1 protein expression levels in DAOY and D283 cells were determined by western blot. GAPDH was used as a loading control. A graphical representation of the western blot analysis is shown in the figure below. (C) The relative Gfi1 mRNA expression levels in DAOY and D283 cells were determined by qRT-PCR. (D) The luciferase activities in DAOY cells were analysed 48 hours after the cotransfection of miR-495 mimics and either the wild-type or mutant Gfi1 3'UTR. (E) Correlation of the relative expression levels of miR-495 compared with the immunoreactive scores of Gfi1 in corresponding medulloblastoma tissues. ${ }^{*} \mathrm{P}<0.05 ;{ }^{* *} \mathrm{P}<0.001$.

significant predictor of prognosis in medulloblastoma patients $(\mathrm{p}=0.027, \mathrm{HR}=0.267,95 \% \mathrm{CI}$ $=0.083-0.859$, Table 2).

\section{Gfi1 is a direct target of miR-495}

The bioinformatics analysis of potential miR-495 targets by PicTar (http://pictar. bio.nyu.edu/), TargetScan (http://genes.mit.edu/tscan/targetscanS.html) and Human microRNA Targets (http://www.microrna.org/) revealed Growth Factor Independence 1 (Gfi1) as a candidate (Fig. 3A). To address whether miR-495 regulates Gfi1, we transfected DAOY and D283 cells with miR-495 mimics and miR-NC, and the transcript and protein expression levels of Gfi1 were detected by quantitative RT-PCR and western blot, respectively. As illustrated in Figure 3, the overexpression of miR-495 yielded a marked reduction in Gfi1 expression in DAOY and D283 cells (Fig. 3B). However, a significant difference in the Gfi1 transcript level was not observed between the miR-495-transfected cells and the miR-NCtransfected cells (Fig. 3C). Taken together, the results show that miR-495 regulates the Gfi1 levels by translational suppression rather than by mRNA degradation.

To confirm whether Gfi1 is a direct target of miR-495, we generated a luciferase reporter plasmid containing the 3'UTR of Gfi1. As a control, we constructed a mutant reporter plasmid in which the seed binding region on the 3'UTR of Gfi1 was mutated. miR-495 or miR-NC was co-transfected with the reporter vectors into DAOY cells, and luciferase activity was measured $48 \mathrm{~h}$ post-transfection. We observed that miR-495 overexpression led to a significant repression in the luciferase activity of the wild-type reporter plasmid in DAOY cells compared with that obtained after miR-NC transfection (Fig. 3D). Of note, mutation of the seed sequence within the 3'-UTR of Gfi1 completely abrogated this suppression effect of miR-495. These results indicate that Gfi1 is a specific target of miR-495. 
Gfi1 protein level inversely correlates with the miR-495 level in medulloblastoma specimens

The above-mentioned results suggest that miR-495 post-transcriptionally regulates Gfi1. Thus, we hypothesized the existence of an inverse correlation between the miR495 expression level and the Gfi1 protein level in medulloblastoma specimens. We tested this hypothesis in 62 medulloblastoma samples by RT-PCR and immunohistochemistry. The results revealed an inverse relationship (Kendall's $\mathrm{R}=-0.571$ ) between the miR-495 expression level and the Gfi1 protein level in medulloblastoma specimens (Fig. 3E).

\section{Discussion}

The current study provides evidence that miR-495 is significantly downregulated in medulloblastoma compared with normal cerebellum tissues and that patients with lower miR-495 expression than the median levels are associated with decreased survival times relative to those with miR-495 expression levels higher than the median. Furthermore, the multivariate Cox proportional hazards analysis showed that miR-495 can act as an independent prognostic biomarker. Our experiment offers the first demonstration that miR495 directly interacts with the Gfi1 3'UTR to regulate Gfi1 at the post-transcriptional level and that the expression level of miR-495 is inversely correlated with the Gfi1 protein level in medulloblastoma specimens.

The outcome of miR-495 function appears to be tumour-specific, i.e., it can be either an oncogene or a tumour suppressor. miR-495 reveals tumour-suppressor activity by targeting PBX3 and MEIS1 in MLL-rearranged leukaemia [15]. The overexpression of miR-495 can significantly inhibit the migration and invasion of gastric cancer cells [18]. In contrast, miR495 can contribute to tumour cell invasion and metastasis via the suppression of MAT1A in hepatocellular carcinoma, thereby functioning as an oncogenic miRNA [21]. In addition, in breast cancer stem cells, the ectopic expression of miR-495 promotes colony formation in vitro and tumourigenesis in vivo through suppressing E-cadherin and REDD1. Moreover, recent studies have revealed that miR-495 participates in regulating the differentiation of embryonic stem cells and mesenchymal stem cells $[22,23]$. The evidence suggests that miR495 plays additional unexpected important roles in development and tumourigenesis. In our study, the expression of miR-495 was found to be significantly downregulated, and the oncogene Gfi1 was found to be its direct target. Thus, miR-495 appears to function as tumour suppressor in medulloblastomas, similar to its role in glioma, which is another common malignant tumour of the central nervous system [19].

We determined that the Gfi1 protein level was markedly reduced upon miR-495 restoration, but the Gfi1 mRNA level was not significantly changed, supporting the finding that miR-495 negatively regulates Gfi1 by translational suppression rather than by mRNA degradation. The results of the luciferase reporter assay further confirmed that miR-495 specifically acts on the 3'UTR of Gfi1. Thus, we hypothesize that the effect of miR-495 on medulloblastoma may result from the inhibition of Gfi1. In fact, recently, Northcott et al. demonstrated that Gfi1 plays an oncogenicity role specifically in group 3 and 4 subgroup medulloblastomas, which have the poorest outcomes [24]. So it may be that low miR-495 levels are an indicator of group 3/4 medulloblastomas. But, as the limitation of technology, molecular subgroups of medulloblastoma didn't be identified in our study. Moreover, Gfi1 plays a critical role as a transcription repressor in the development and function of hematopoietic stem cells, B and T cells, dendritic cells, granulocytes and macrophages. Gfi1 is required for the development and maintenance of lymphoid neoplasia, such as ALL [25, 26]. A previous study conducted by Khandanpour showed that the inhibition of Gfi1 can not only cure mice from ALL but also block the expansion of human primary ALL cells [27]. In the immune system, Gfi1 is required for T lymphopoiesis as well as mature CD4+ and CD8+ T cell function and maintenance $[28,29]$. In addition, Gfi1 has been implicated in the growth and differentiation of various types of cells [30-32], and its dysregulation is involved in other solid tumours. For example, Gfi1 functions downstream of Math1 in intestinal secretory lineage 
differentiation, suggesting a potential role for Gfi1 in intestinal malignancies. In prostate cancer, Gfi1 may play a role in the repression of 25-hydroxyvitamin D 1alpha-hydroxylase (CYP27B1) [33]. Furthermore, Gfi1 is also a master regulator of microRNAs. Velu and colleagues reported that Gfi1 can regulate miR-21 and miR-196b to control myelopoiesis $[34,35]$. The evidence suggests that the regulatory relationships between Gfi1 and miRNAs are very complex and thus play various biological effects in different tissues and organs.

In conclusion, we present the first demonstration that miR-495 is significantly downregulated in medulloblastoma and that miR-495 is an independent prognostic biomarker for medulloblastoma. miR-495 negatively regulates Gfi1 by specifically acting on the 3'UTR of Gfi1. Thus, miR-495 can be potentially used to predict the prognosis and treatment response in individual medulloblastoma patients.

\section{Disclosure Statement}

None declared.

\section{Acknowledgments}

This work was supported by the Foundation of Health and Family Planning Commission of Heilongjiang Province (No. 2012-711 and No.2015-037) and the Specialized Research Fund for the Doctoral Program of Higher Education (No. 20122307120031).

\section{References}

-1 Northcott PA, Jones DT, Kool M, Robinson GW, Gilbertson RJ, Cho YJ, Pomeroy SL, Korshunov A, Lichter P, Taylor MD, Pfister SM: Medulloblastomics: the end of the beginning. Nat Rev Cancer 2012;12:818-834.

-2 Polkinghorn WR, Tarbell NJ: Medulloblastoma: tumorigenesis, current clinical paradigm, and efforts to improve risk stratification. Nat Clin Pract Oncol 2007;4:295-304.

-3 MacDonald TJ, Aguilera D, Castellino RC: The rationale for targeted therapies in medulloblastoma. Neuro-Oncology 2014;16:9-20.

4 Gerber NU, Mynarek M, von Hoff K, Friedrich C, Resch A, Rutkowski S: Recent developments and current concepts in medulloblastoma. Cancer Treat Rev 2014;40:356-365.

-5 Sun H, Xin J, Lu Z, Wang N, Liu N, Guo Q. Potential molecular mechanisms for improved prognosis and outcome with neoadjuvant chemotherapy prior to laparoscopical radical hysterectomy for patients with cervical cancer. Cell Physiol Biochem 2013;32:1528-1540.

-6 Li B, Sun M, Gao F, Liu W, Yang Y, Liu H, Cheng Y, Liu C, Cai J: Up-regulated expression of miR-23a/b targeted the pro-apoptotic Fas in radiation-induced thymic lymphoma. Cell Physiol Biochem 2013;32:1729-1740.

7 Han ZB, Yang Z, Chi Y, Zhang L, Wang Y, Ji Y, Wang J, Zhao H, Han ZC: MicroRNA-124 suppresses breast cancer cell growth and motility by targeting CD151. Cell Physiol Biochem 2013;31:823-832.

-8 Wu N, Zhang C, Bai C, Han YP, Li Q. MiR-4782-3p inhibited non-small cell lung cancer growth via USP14. Cell Physiol Biochem 2014;33:457-467.

-9 Pan W, Wang H, Jianwei R, Ye Z. MicroRNA-27a promotes proliferation, migration and invasion by targeting MAP2K4 in human osteosarcoma cells. Cell Physiol Biochem 2014;33:402-412.

- 10 Xi Y, Nakajima G, Gavin E, Morris CG, Kudo K, Hayashi K, Ju J: Systematic analysis of microRNA expression of RNA extracted from fresh frozen and formalin-fixed paraffin-embedded samples. RNA 2007;13:1668-1674. 


\section{Cellular Physiology Cell Physiol Biochem 2015;36:1430-1439 \begin{tabular}{l|l} 
and Biochemistry Publisned onIIne: July U6, 2015, 2015 & $\begin{array}{l}\text { C) 2015 S. Karger AG, Basel } \\
\text { www.karger.com/cpb }\end{array}$ \\
\hline
\end{tabular} \\ Wang et al: MIR-495 IS A Predictive Biomarker of Medulloblastoma}

-11 Kunder R, Jalali R, Sridhar E, Moiyadi A, Goel N, Goel A, Gupta T, Krishnatry R, Kannan S, Kurkure P, Deopujari C, Shetty P, Biyani N, Korshunov A, Pfister SM, Northcott PA, Shirsat NV: Real-time PCR assay based on the differential expression of microRNAs and protein-coding genes for molecular classification of formalin-fixed paraffin embedded medulloblastomas. Neuro-Oncology 2013;15:1644-1651.

12 Zhao S, Yang G, Mu Y, Han D, Shi C, Chen X, Deng Y, Zhang D, Wang L, Liu Y, Hou X, Wang C, Wu J, Liu H, Wang L, Zhang G, Qi J, Fang X, Shi C, Ai J: MiR-106a is an independent prognostic marker in patients with glioblastoma. Neuro-Oncology 2013;15:707-717.

-13 Fiaschetti G, Abela L, Nonoguchi N, Dubuc AM, Remke M, Boro A, Grunder E, Siler U, Ohgaki H, Taylor MD, Baumgartner M, Shalaby T, Grotzer MA: Epigenetic silencing of miRNA-9 is associated with HES1 oncogenic activity and poor prognosis of medulloblastoma. Br J Cancer 2014;110:636-647.

- 14 Garzia L, Andolfo I, Cusanelli E, Marino N, Petrosino G, De Martino D, Esposito V, Galeone A, Navas L, Esposito S, Gargiulo S, Fattet S, Donofrio V, Cinalli G, Brunetti A, Vecchio LD, Northcott PA, Delattre O, Taylor MD, Iolascon A, Zollo M.: MicroRNA-199b-5p impairs cancer stem cells through negative regulation of HES1 in medulloblastoma. PloS One 2009;4:e4998.

15 Jiang X, Huang H, Li Z, He C, Li Y, Chen P, Gurbuxani S, Arnovitz S, Hong GM, Price C, Ren H, Kunjamma RB, Neilly MB, Salat J, Wunderlich M, Slany RK, Zhang Y, Larson RA, Le Beau MM, Mulloy JC, Rowley JD, Chen J: MiR-495 is a tumor-suppressor microRNA down-regulated in MLL-rearranged leukemia. Proc Natl Acad Sci USA 2012;109:19397-19402.

-16 Chu H, Chen X, Wang H, Du Y, Wang Y, Zang W, Li P, Li J, Chang J, Zhao G, Zhang G: MiR-495 regulates proliferation and migration in NSCLC by targeting MTA3. Tumour Biol 2014;35:3487-3494.

17 Formosa A, Markert EK, Lena AM, Italiano D, Finazzi-Agro' E, Levine AJ, Bernardini S, Garabadgiu AV, Melino G, Candi E: MicroRNAs, miR-154, miR-299-5p, miR-376a, miR-376c, miR-377, miR-381, miR487b, miR-485-3p, miR-495 and miR-654-3p, mapped to the 14q32.31 locus, regulate proliferation, apoptosis, migration and invasion in metastatic prostate cancer cells. Oncogene 2014;33:5173-5182.

-18 Li Z, Cao Y, Jie Z, Liu Y, Li Y, Li J, Zhu G, Liu Z, Tu Y, Peng G, Lee DW, Park SS: miR-495 and miR-551a inhibit the migration and invasion of human gastric cancer cells by directly interacting with PRL-3. Cancer Lett 2012;323:41-47.

-19 Chen SM, Chen HC, Chen SJ, Huang CY, Chen PY, Wu TW, Feng LY, Tsai HC, Lui TN, Hsueh C, Wei KC: MicroRNA-495 inhibits proliferation of glioblastoma multiforme cells by downregulating cyclindependent kinase 6. World J Surg Oncol 2013;11:87.

20 Song L, Li Y, Li W, Wu S, Li Z: miR-495 enhances the sensitivity of non-small cell lung cancer cells to platinum by modulation of copper-transporting P-type adenosine triphosphatase A (ATP7A). J Cell Biochem 2014;115:1234-1242.

-21 Yang H, Cho ME, Li TW, Peng H, Ko KS, Mato JM, Lu SC: MicroRNAs regulate methionine adenosyltransferase 1A expression in hepatocellular carcinoma. J Clin Invest 2013;123:285-298.

-22 Yang D, Wang G, Zhu S, Liu Q, Wei T, Leng Y, Duan T, Kang J: MiR-495 suppresses mesendoderm differentiation of mouse embryonic stem cells via the direct targeting of Dnmt3a. Stem Cell Res 2014;12:550-561.

23 Lee S, Yoon DS, Paik S, Lee KM, Jang Y, Lee JW: microRNA-495 inhibits chondrogenic differentiation in human mesenchymal stem cells by targeting Sox9. Stem Cells Dev 2014;23:1798-1808.

24 Northcott PA, Lee C, Zichner T, Stütz AM, Erkek S, Kawauchi D, Shih DJ, Hovestadt V, Zapatka M, Sturm D, Jones DT, Kool M, Remke M, Cavalli FM, Zuyderduyn S, Bader GD, VandenBerg S, Esparza LA, Ryzhova M, Wang W, Wittmann A, Stark S, Sieber L, Seker-Cin H, Linke L, Kratochwil F, Jäger N, Buchhalter I, Imbusch CD, Zipprich G, Raeder B, Schmidt S, Diessl N, Wolf S, Wiemann S, Brors B, Lawerenz C, Eils J, Warnatz HJ, Risch T, Yaspo ML, Weber UD, Bartholomae CC, von Kalle C, Turányi E, Hauser P, Sanden E, Darabi A, Siesjö P, Sterba J, Zitterbart K, Sumerauer D, van Sluis P, Versteeg R, Volckmann R, Koster J, Schuhmann MU, Ebinger M, Grimes HL, Robinson GW, Gajjar A, Mynarek M, von Hoff K, Rutkowski S, Pietsch T, Scheurlen W, Felsberg J, Reifenberger G, Kulozik AE, von Deimling A, Witt O, Eils R, Gilbertson RJ, Korshunov A, Taylor MD, Lichter P, Korbel JO, Wechsler-Reya RJ, Pfister SM: Enhancer hijacking activates GFI1 family oncogenes in medulloblastoma. Nature 2014;511:428434. 


\section{Cellular Physiology Cell Physiol Biochem 2015;36:1430-1439

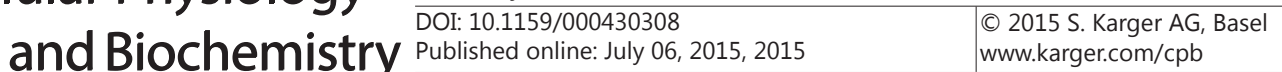 \\ Wang et al: MIR-495 IS A Predictive Biomarker of Medulloblastoma}

25 Khandanpour C, Kosan C, Gaudreau MC, Dührsen U, Hébert J, Zeng H, Möröy T: Growth factor independence 1 protects hematopoietic stem cells against apoptosis but also prevents the development of a myeloproliferative-like disease. Stem Cells 2011;29:376-385.

-26 Khandanpour C, Sharif-Askari E, Vassen L, Gaudreau MC, Zhu J, Paul WE, Okayama T, Kosan C, Möröy T: Evidence that growth factor independence $1 \mathrm{~b}$ regulates dormancy and peripheral blood mobilization of hematopoietic stem cells. Blood 2010;116:5149-5161.

-27 Khandanpour C, Phelan JD, Vassen L, Schütte J, Chen R, Horman SR, Gaudreau MC, Krongold J, Zhu J, Paul WE, Dührsen U, Göttgens B, Grimes HL, Möröy T: Growth factor independence 1 antagonizes a p53-induced DNA damage response pathway in lymphoblastic leukemia. Cancer Cell 2013;23:200214.

28 Chalmin F, Mignot G, Bruchard M, Chevriaux A, Végran F, Hichami A, Ladoire S, Derangère V, Vincent J, Masson D, Robson SC, Eberl G, Pallandre JR, Borg C, Ryffel B, Apetoh L, Rébé C, Ghiringhelli F: Stat3 and Gfi-1 transcription factors control Th17 cell immunosuppressive activity via the regulation of ectonucleotidase expression. Immunity 2012;36:362-373.

29 Spooner CJ, Lesch J, Yan D, Khan AA, Abbas A, Ramirez-Carrozzi V, Zhou M, Soriano R, EasthamAnderson J, Diehl L, Lee WP, Modrusan Z, Pappu R, Xu M, DeVoss J, Singh H: Specification of type 2 innate lymphocytes by the transcriptional determinant Gfi1. Nat Immunol 2013;14:1229-1236.

-30 Nakazawa Y, Suzuki M, Manabe N, Yamada T, Kihara-Negishi F, Sakurai T, Tenen DG, Iwama A, Mochizuki M, Oikawa T: Cooperative interaction between ETS1 and GFI1 transcription factors in the repression of Bax gene expression. Oncogene 2007;26:3541-3550.

-31 Kazanjian A, Wallis D, Au N, Nigam R, Venken KJ, Cagle PT, Dickey BF, Bellen HJ, Gilks CB, Grimes HL: Growth factor independence- 1 is expressed in primary human neuroendocrine lung carcinomas and mediates the differentiation of murine pulmonary neuroendocrine cells. Cancer Res 2004;64:68746882.

-32 Wallis D, Hamblen M, Zhou Y, Venken KJ, Schumacher A, Grimes HL, Zoghbi HY, Orkin SH, Bellen HJ: The zinc finger transcription factor Gfi1, implicated in lymphomagenesis, is required for inner ear hair cell differentiation and survival. Development 2003;130:221-232.

-33 Dwivedi PP, Anderson PH, Omdahl JL, Grimes HL, Morris HA, May BK: Identification of growth factor independent-1 (GFI1) as a repressor of 25-hydroxyvitamin D 1-alpha hydroxylase (CYP27B1) gene expression in human prostate cancer cells. Endocr Relat Cancer 2005;12:351-365.

- 34 Velu CS, Baktula AM, Grimes HL: Gfi1 regulates miR-21 and miR-196b to control myelopoiesis. Blood 2009;113:4720-4728.

-35 Velu CS, Chaubey A, Phelan JD, Horman SR, Wunderlich M, Guzman ML, Jegga AG, Zeleznik-Le NJ, Chen J, Mulloy JC, Cancelas JA, Jordan CT, Aronow BJ, Marcucci G, Bhat B, Gebelein B, Grimes HL: Therapeutic antagonists of microRNAs deplete leukemia-initiating cell activity. J Clin Invest 2014;124:222-236. 